\title{
Challenges and Strategies of Global Branding In Indian Market
}

\author{
Sandeep Saxena \\ (M.B.A., Gautam Buddha Technical University, Lucknow, India)
}

\begin{abstract}
India is a developing country. In today's scenario brands are the basis of consumer relationship. Global brand is a product that adds other dimensions that differentiate it in some way from other products designed to satisfy the same need. Global Marketing needs clear vision regarding the 4P's of marketing mix in the context of International market. Brand is the biggest asset of any company. A global brand should provide relevant meaning and experience to people across multiple societies. The perception of quality that is associated with the global brands is difficult to unlock but it's easier to create a blue ocean of opportunities for Indian brands. Branding strategy must be devised, after considering the brands own capabilities and competencies, strategies of competing brands, and the outlook of consumers, which are largely formed by experiences in their respective societies. The marketing policy has huge influence, when there is right translation of brand into the marketing mix. The main focus of this paper is on Global Branding and challenges in it. It also looks into six challenges (6E's) and strategies of branding in Global Market.

Keywords: Branding strategies, Global Brand, 6E's, International Market, Brand Domain, Brand Reputation.
\end{abstract}

\section{Introduction}

A number of well-known global brands have derived much of their sales and profits from nondomestic markets for years, for example, Coca-Cola, Shell, Bayer, Rolex, Marlbordo, Pampers, and Mercedes-Benz to name a few. Brands such as Apple computers, L'Oreal cosmetics, and Nescafe instant coffee have become fixtures on the global landscape. The successes of these brands have provided encouragement to many firms to market their brands internationally. A number of other forces have also contributed to the growing interest in global marketing. These are perception of slow growth and increased competition in domestic markets, Belief in enhanced overseas growth and profit opportunities, Desire to reduce costs from economies of scale, Need to diversify risk and Recognition of global mobility of customers. Today companies going global, continuously innovate their strategies for worldwide success. Global Marketing needs clear vision regarding the 4P's i.e., Product modification, Pricing issues, Promotion mix strategies to adhere to the cultural sentiments, language and lifestyle patterns of foreign consumers and right distribution channel to penetrate deeper. Other challenges include suitable Packaging and building Brand for acceptance in the foreign market. All these require Marketing Research followed by segmenting, targeting and positioning of the markets. The debate on Standardization Vs Customization exists. It is argues that premium brands and experiential brands opt for standardization, while FMCG brands and other need a customized approach in diverse markets.

\section{The Power of Branding}

Branding has been around for centuries as a means to distinguish the goods of one producer from those of another. In fact, the word brand is derived from the Old Norse word bandr, which means "to burn," as brands were and still are the means by which owners of livestock mark their animals to identify them.

Brands have become increasingly important components of culture and the economy, now being described as "cultural accessories and personal philosophies". Brand Building process is a value addition technique which projects the image of the product, the company and the country at large A Brand is a name or trademark connected with a product or producer. Brands have become increasingly important components of culture and the economy, now being described as "cultural accessories and personal philosophies" "Branding strategy' is vital to direct global marketing efforts. Brand strategy aids businesses in achieving their targeted performance. Brand knowledge, brand applications, brand relationships, brand preferences and brand loyalty impacts on building up of brand equity. In trying to create strong brand equity, company should be Interested in assessing the degree of customer brand dependence. The brand strength depends on the perception of customers. Satisfied and loyal customers indicate positive perceptions of brand. Branding is more powerful than it is normally perceived and those companies which realized this have capitalized by building a strong Global Brand. A strong brand reassures the customer; it gives confidence in terms of the quality and satisfaction that can be anticipated from buying it. From all of this comes the possibility of long-term profits. Many brands are household names today, but the concept of brand management has moved beyond the household goods categories. Brand is the biggest asset of any company. Google is a strong global brand with high brand value and established brand image. A global brand is defined as the worldwide use of a name, term, sign, symbol (visual and/or auditory), design, or combination thereof intended to identify goods or services of one seller and 
to differentiate them from those of competitors. Much like the experience with global products, there is no single answer to the question of whether or not to establish global brands. A global brand should provide relevant meaning and experience to people across multiple societies. A global brand is the worldwide use of a name, term, sign, symbol (visual and/or auditory), design, or combination thereof intended to identify goods or services of one seller and to differentiate them from those of competitors. Even when a company has promoted its global brand name worldwide, it is difficult to standardize its brand associations in all countries. All leading global brands have one thing in common, i.e., they share a set of 'dimensions' which others need to understand, master and mange. Physical and psychological attributes of the brand must be well defined.

- How well does the product perform?

- How efficient is the integrated marketing communication strategy in creating the right brand appeal to the foreign consumers?

- How competitive is its price may require some adaptation to local market conditions and culture?

There are four functions of the mind-thinking, sensation, feeling and intuition. The psychological attributes deals with these four aspects in a consumer. A clear communication of the Brand meaning and value forms the right Brand Image in the consumer's mind. Harley Davidson is a brand with the Image of ruggedness, tough and masculine personality. The trend today is toward a "borderless world."Global branding strategies consist of using the same brand name or logo worldwide. Companies want to leverage the creation of such brand names across many markets, because the launching of new brands requires a considerable marketing investment. Global branding strategies tend to be advisable if the target customers travel across country borders and will be exposed to products elsewhere. Global branding strategies also become important if target customers are exposed to advertising worldwide. This is often the case for industrial marketing customers who may read industry and trade journals from other countries. Increasingly, global branding has become important also for consumer products where cross-border advertising through international TV channels has become common. Even in some markets such as Eastern Europe, many consumers had become aware of brands offered in Western Europe before the liberalization of the economies in the early 1990s. Global branding allows a company to take advantage of such existing goodwill. Companies pursuing global branding strategies may include luxury product marketers who typically face a large fixed investment for the worldwide promotion of a product.

\section{Objective Of Study}

- To identify the Brand and Marketing strategies for global branding in India.

- To identify six challenges (6 E's) in global marketing in India.

- To find out advantages and disadvantages of global brand in India.

\section{The Brand Environment}

More factors influence a brand than the business strategy and the subsequent Efforts of the organization and its affiliates to bring about the brand, as described in the previous paragraph. A brand operates in an environment consisting of, on the one hand, the elements of the strategic planning cycle, and on the other hand, organizational conventions, competitive forces, market structures, cultural factors, consumer motivation and media attention: the lenses and filters through which consumers perceive and experience the brand.

\subsection{Perception of consumers}

Perception of consumers about a product's quality/performance is more important than the actual. It matters little whether the brand really is the best in a product category, what matters most is whether the consumers perceive the brand to be the best or not. Intel, Nike and Tiffany are some global brands which enjoy the benefit of strong, favorable consumer perception. When entering a foreign market with our Brand, the culture, language and mindset of people in that country must be studied first and then appropriate Brand communication efforts must be taken. Let us see the experiences of a global brand in Chinese market-

\subsubsection{Experiences of Global Brands in China:}

Linguistic differences between Chinese and English are wide and deep, making translation of brand names difficult. Cultural context, pronunciation, written vs. oral language, and meaning of characters are just a few examples of such difficulties. International brands often need to be both globally consistent and locally relevant. A better understanding of the Chinese language and its membership in a linguistic group are relevant to international branding managers wishing to position their products in the local marketplace. The experience of one International brands is as follows-

Toyota, the famous SUV brand of Japan was faced with severe Government censoring and public protests due to its advertising content representation and meaning of the name. Toyota Chinese branding of the SUV Prado, launched by Saatchi \& Saatchi, Beijing, was translated to Ba Dao which roughly translates to "the mighty rule," or "rule by force." This masculine depiction of the japans SUV was also accompanied by 
advertises media that showed two stone lions saluting and bowing to the car. It was a cultural blunder in the Chinese market.

\section{Brand strategies for global brand}

There are four broad brand strategy areas that can be employed.

\subsection{Brand Domain}

Brand domain specialists are experts in one or more of the brand domain aspects (products/services, media, distribution, solutions). A brand domain specialist tries to pre-empt or even dictate particular domain developments. This requires an intimate knowledge, not only of the technologies shaping the brand domain, but also of pertinent consumer behavior and needs. The lifeblood of a brand domain specialist is innovation and creative use of its resources. A brand domain specialist is like a cheetah in the Serengeti preying on impala and gazelle. The cheetah is a specialist hunter with superior speed to chase, and the claws and teeth to kill these animals. The cheetah is also very familiar with the habits of its

prey. It finds ways of approaching, singling out and capturing its prey. The cheetah is one of the most accomplished of hunters within the wild cat species; it catches up to $70 \%$ of prey that it hunts.

\subsection{Brand Reputation}

Brand reputation specialists use or develop specific traits of their brands to support their authenticity, credibility or reliability over and above competitors. A brand reputation specialist needs to have some kind of history, legacy or mythology. It also needs to be able to narrate these in a convincing manner, and be able to live up to the resulting reputation. A brand reputation specialist has to have a very good understanding of which stories will convince consumers that the brand is in some way superior. A brand reputation specialist is like a horse. It can be pure-bred, have a certain nobility and bearing, and exhibit qualities that can be traced back to these (e.g. grace, speed, temperament, looks). Like a horse, the brand reputation specialist can also thrive on association with celebrities.

\subsection{Brand Affinity}

Brand affinity specialists bond with consumers based on one or more of a range of affinity aspects. A brand affinity specialist needs to outperform competition in terms of Building relationships with consumers. This means that a brand affinity specialist needs to have a distinct appeal to consumers, be able to communicate with them affectively, and provide an experience that reinforces the bonding process. A brand affinity specialist is like a pet dog. A dog is generally considered to be man's best friend, due to its affection, its obedience, its loyalty, the status and the protection it provides to its owners. Different kinds of dogs will command a different form of affection.

\subsection{Brand Recognition}

Brand recognition specialists distinguish themselves from competition by raising their profiles among consumers. The brand recognition specialist either convinces consumers that it is somehow different from competition, as is the case for niche brands, or rises above the melee by becoming well known among consumers than competition. The latter is particularly important in categories where brands have few distinguishing features in the minds of consumers. In some cases, a brand recognition specialist needs to be able to outspend competition to gain unbeatable levels of awareness. In other cases, a brand recognition specialist needs to convince a loyal following of consumers that it is unique.

\section{Impact On Brand Strategy}

Brand strategy is not a given and needs to be constantly reassessed. Brand managers must decide what is the best course of action for their brands in particular markets, based on an analysis of the relevant internal and external influences on the brands.

\subsection{Domain Specialists}

Domain specialists generally require economies of scale to be able to sustain their investments in constant innovation. Brand proposition standardization or harmonization is part of this drive towards economies of scale. Domain specialists tend to centralize brand management, which leaves little room for local adaptation.

\subsection{Reputation Specialists}

Reputation specialists are a diverse bunch, some of whom rely heavily upon their pedigrees while others leverage their connections to celebrities, and yet others build on a promise that they have demonstrably been able to keep. Reputation specialists are often good at tweaking their brands to ensure relevance to consumers in specific societies. This means that brand and marketing management need to be largely localized, 
with a largely a guiding task for global management. It also means that competencies such as consumer understanding and narration need to be available locally.

\subsection{Affinity Specialists}

Affinity specialists are able to pluck the heartstrings of consumers. They way they do so differ markedly between brands, but the common result are unrivalled brand loyalty. Some affinity specialists are able to standardize their brands across societies by using themes that are common across various societies. For instance, Mercedes is a brand that many (successful) people around the world wish to be associated with. However, most affinity specialists need local brand management in order to be able to build a worthwhile rapport with consumers. Affinity specialists need to get close to consumers to be able to connect with them. This closeness requires affinity specialists to understand exactly which conventions can and cannot be challenged. This also means that the brand's organization must encourage local brand management initiatives.

\subsection{Recognition Specialists}

Recognition specialists succeed by using two aspects, namely consumer's .Inability to discriminate between a multitude of brands in a category and their inability to know more than a few brands in a category. In some categories it is difficult for consumers to understand the differences between brands. Subsequently consumers will opt for those brands that they know, the ones they hear of often. These will usually be the big players in a market. For instance, most people are not able to fathom the differences in the propositions offered by various banks. What they are aware of are the well-known banks. This awareness breeds confidence and leads most people to choose one of these. A more extreme case is the mass wine category, which is teeming with unfamiliar brands. By raising its profile, the Ernest \& Julio Gallo brand provides a safe-haven for consumers. It is a brand that they can trust to provide a consistent quality at an agreeable price.

\section{Marketing Strategies Of Global Brands In Indian Markets}

With increasing globalization and international trade, a number of international brands are entering into India which is one of the fastest growing and highly competitive markets in the world. Though, most of the global firms failed to understand the needs of Indian consumers as well as the market characteristics but there are a few of them who have been successful in positioning their brands into the Indian market because they attempt to understand well the needs of target group before introducing a brand into the market. Even some of the most successful brands in today's time had committed several blunders or mistake while initially entering into Indian market. For instance, Kellogg's, McDonald's, LG, Reebok and Coca-Cola are among such global brands who initially introduced standard products by following standardized global strategies but later realized their mistakes and thus modified their product or services according to the needs of Indian consumers and became successful. In today's scenario, for any Global brand to succeed in Indian markets, the companies need to shift their focus from forming global strategies for the overall market, to the strategies that adapt to the local market conditions in the India. The Global firms operating in India must try to be as local as they can be, by converting themselves into Global brands i.e. being global at heart. The companies can achieve these objective, either by using local manufacturing, producing Indianised variants of their products to take care of local consumers tastes, to use local celebrities as brand ambassadors, and tackle the issue of price sensitivity of the Indian consumers by launching value for money products which are affordable for the masses and forming long term relationships with intermediaries in the market and instill in them a sense of confidence that they are your brand's partners in your journey towards success and they too will benefit if you as a company will succeed and if your brands succeed in Indian market. It was beautifully illustrated in an article titled "Made In India, Only For India" recently published in 'The Strategist' stated that "Now for most of the successful MNCs operating in India, exclusively for India has become an integral part of their overall product development strategy". Through this paper, it is attempted to highlight that MNCs must introduce the products or services matching to the needs of Indian markets in order to be successful. For instance, Honda Motorcycles recently launched bike "Dream Yuga" to tap the entry level segment to take on its competitor and erstwhile joint venture partner "Hero Moto Corps' that holds leading market share in this segment. Similarly, GE Healthcare launched an Electrocardiogram (ECG) machine especially to be used by rural markets where the clinics do not have much space to operate those complex ECG machines which also runs on battery to overcome the electricity problem caused by the frequent power-cuts in Indian rural markets. Even Korean automobile company launched Hyundai Eon in the Indian market after conducting a research which revealed to them a slight change in preferences of Indian consumers i.e. they now valued mileage, then styling, space, interiors and then finally pricing while purchasing a care, while it earlier used to be mileage, price, styling and interior space, and it was based on this research only that Hyundai Eon was launched in the Indian markets. So this new mantra of being global but acting locally is being adopted by most of the MNCs to succeed in the Indian market. The MNCs' and their brands that are successful in Indian markets are switching to this strategy of presenting themselves as a local company so that people can identify themselves with these firms as their own and this is the reason that why 
most of the global firms are now focusing on local promotions, local products, pricing strategies as per local requirements and local distribution for Indian markets instead of using their global marketing communications mix to attract the Indian consumers to their brands. The growth for these brands in Indian markets has been increasing throughout depending on how they are tapping the markets by offering more and more regional flavors and tastes which are pushing these brands forward.

\section{Six Challenges In Global Branding} strong brand.

Strong brands requires a clear strategic approach to handle the six efforts (6Es) involved in creating

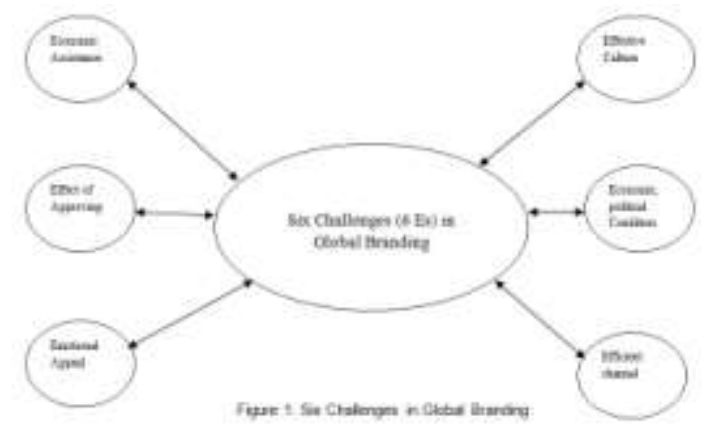

\subsection{Economic Assistance}

The main challenge faced by the brand leaders is to focus on the short term returns. Brand is a long term asset, introduction of price, discount or freebie promotion for initial acceptance of the product may lead to brand dilution and failure in the long run.

\subsection{Effect of Approving}

There must be consistency in quality/performance, if not betterment so as to sustain the growing complexity of International market in terms of Consumer's changing tastes and multiplying competition. The company must continuously innovate and maintain good customer relations though their consumer touches points, so as to create brand loyalty among existing users.

8.3 Emotional Appeal

Emotional appeal is essential to communicate the Brand message. Consider the number of media options available to consumers-200 or more television channels, Internet, Newspaper, magazines.

\subsection{Effective Culture}

Culture refers to how people in a society interact, what they believe. How they make decisions and what meanings they attach to certain representations. Cultures are not static, but develop through intergenerational and interpersonal learning and experience.

8.5 Economic, Legal and Political conditions

Condition implies the Economic, Legal and Political conditions prevailing in a foreign market. Law related to Advertising content, product specifications, distribution options, etc vary from one country to another. The Economic condition in UK made LG play down its tagline 'Life is Good' in Advertisements due to recent credit crunch.

8.6 Efficient distribution channel

Formation of distribution channel alliances in a foreign market. A distribution channel decision is vital and rigid, that it expensive to change, once decision is made.

\section{What Makes A Strong Global Brand?}

To create a strong a global brand and maximize brand equity, marketing manager must do the following-

- Understand brand meaning and market appropriate product in an appropriate manner

- Properly position the brand

- Provide superior delivery of desired benefit

- Employee a full range of complementary brand element and supporting marketing activities

- Embrace integrated marketing communications and communicate with a consistent voice

- Measure consumer perception of value and develop a pricing strategy accordingly

- Establish credibility and appropriate brand personality and imagery

- Maintain innovation and relevance for the brand

- Strategically design and implement a brand hierarchy and brand portfolio

- Implement a brand equity management system to ensure that marketing actions properly reflect the brand equity concept 


\section{Advantages Of Global Brand}

- Economies of scale in production and distribution

- Global brand building increases cash flow efficiency by ensuring timely payment and receipt of cash. There is more reliability and the Brand itself is a big intangible asset which can be valued in millions.

- Lower marketing costs

- Global branding helps to break entry barriers when entering foreign markets due to its reputation. It also helps to defend itself from local competitors or new entrants.

- Power and scope Consistency in brand image.

- A strong global brand has a premium value in the minds of foreign consumer. It creates favorable associations in their minds, which enables the marketer to fix a premium price and enjoy optimum profitability. Even water when branded as Aquafina or kingfisher becomes rich in the image it creates in consumer's mind.

- Ability to leverage good ideas quickly and efficiently.

- It facilitates planning and budgeting of effective Brand building programs.

- Uniformity of marketing practices.

- Synergy is created by appropriate market expansion and collaboration, which would help in innovation and long term growth.

- It reduces the amount of production and marketing investment due to Economies of Scale in carrying out bulk operations.

\section{Disadvantages Of Global Brand}

- Differences in consumer needs, wants, and usage patterns for products

- Differences in consumer response to marketing mix elements

- Differences in brand and product development and the competitive environment

- Differences in the legal environment

- Differences in marketing institutions

- Differences in administrative procedures

\section{Conclusions}

As Indian companies seek to be major players in global markets, one of the key challenges they face is building global brands. Building brands is important - as wages rise with economic development, competing on cost alone may not be sustainable. While brands may not necessarily translate into premium prices, they help companies gain higher market share in a crowded market place as they convey an assurance of quality and reliability. The brand strength depends on the perception of customers. Satisfied and loyal customers indicate positive perceptions of brand. In time when competition is getting powerful, it is imperative for the firm to seriously evaluate factors that are not only important in creating strong brand equity but also assist them in achieving customer satisfaction and loyalty. Branding is a major issue in product strategy. Branding is expensive and time-consuming, and can make or broke a product. The most valuable brands have a brand equity that is considered an important company asset. The best brand name suggest something about the product's benefits; suggest products qualities; are easy to pronounce, recognize, and remember; are distinctive; and do not carry negative meanings or connotations in other countries or languages. The marketing implementation may make or break a brand and is most vital as consumers actually experience the brand through advertising, promotions, purchase and after-sales service. Global marketers need to make a sustainable brand strategy which lists the character traits intended for the brand.

\section{Journal Papers}

\section{References}

[1] Kyung Hoon Kim,Kang Sik Kim,Dong Yul Kim,Jong Ho Kim,Suk Hou Kang (2008): Brand Equity in Hospital Marketing, Journal of Business Research 61, 2008, 75-82.

[2] Manoj Pandey \& Dr. J.K. Raju (2009): Analyzing Relationship between Brand Perception and Customer Loyalty in Life Insurance Industry, The Journal - Contemporary Management Research, Vol.3, No 1, March 2009.

[3] Simonin, Bernared L. \& Julie A. Ruth (1998): Is a Company known by the Company it keeps? Assessing the Spillover Effects of Brand Alliences on Consumer Brand Attitudes, journal of Marketing Research, 35, February 1998, 30-42.

[4] Sweemey, Jillian C., Geoffrey N. Soutrar \& Lester W. Johnson (1999), The role of Perceived Risk in the Quality-value Relationship International Journal of Research in Marketing 10,1999, 23-45.

[5] Tsiros, Micheal \& vikas Mittal (2000), Regret: A Model of its Antecedents \& Consequences in Consumer Decision making, journal of Consumer Research 26, March 2000, 401-417.

[6] Yoo, Boonghee, Naveen Donthy \& Sungho Lee (2000), An Examination of Selected Marketing Mix Elements and Brand Equity, Journal of the academy of Marketing Science, 28(2), 2000, 195-211. 